\title{
UHF meander bowtie antenna for RFID application
}

\author{
Norsaidah Muhamad Nadzir ${ }^{1}$, M.K.A. Rahim ${ }^{2}$, F. Zubir ${ }^{3}$, and H.A. Majid ${ }^{4}$ \\ 1,2,3 Communication Engineering Department, Universiti Teknologi Malaysia, Malaysia. \\ ${ }^{4}$ Research Center for Applied Electromagnetics, Universiti Tun Hussein Onn Malaysia, Malaysia
}

\begin{tabular}{|c|c|}
\hline Article Info & ABSTRACT \\
\hline Article historys: & \multirow{10}{*}{$\begin{array}{l}\text { This paper describes the development of four different ultra-high frequency } \\
\text { (UHF) radio frequency identification (RFID) tag antenna using polycarbonate } \\
\text { material or transparent paper as the substrate and aluminum tape as the } \\
\text { radiating element. The main advantage of the method is that the materials are } \\
\text { easy to obtain where it can be found in any hardware stores or in any general } \\
\text { online shop. Plus, the antennas are designed in such a way that a meander line } \\
\text { is traced along the shape of a bowtie antenna so that the antenna would operate } \\
\text { at UHF band. The results of all four of the tag antenna designs are discussed } \\
\text { and compared using graph obtained from Computer Simulation Technology } \\
\text { (CST) simulation results and measurement results obtained from a portable } \\
\text { Vector Network Analyzer (VNA) for the reflection coefficient, S } \text { S11 and }_{11} \text { an } \\
\text { measurement results taken from VNA in chamber room for the radiation } \\
\text { pattern. Finally, the results show that the measured results are in agreement } \\
\text { with the simulated result and that the UHF RFID tag antennas are able to } \\
\text { operate at UHF RFID band. }\end{array}$} \\
\hline Received Mar 27, 2019 & \\
\hline Revised May 6, 2019 & \\
\hline Accepted May 27, 2019 & \\
\hline \multirow{7}{*}{$\begin{array}{l}\text { Keywords: } \\
\text { CST simulation } \\
\text { Measurement } \\
\text { Polycarbonate material } \\
\text { Tag antenna } \\
\text { UHF RFID }\end{array}$} & \\
\hline & \\
\hline & \\
\hline & \\
\hline & \\
\hline & \\
\hline & $\begin{array}{r}\text { Copyright }(\mathrm{C} 2019 \text { Institute of Advanced Engineering and Science. } \\
\text { All rights reserved. }\end{array}$ \\
\hline \multicolumn{2}{|l|}{ Corresponding Author: } \\
\hline \multicolumn{2}{|c|}{$\begin{array}{l}\text { Norsaidah Muhamad Nadzir, } \\
\text { Communication Engineering Department, } \\
\text { Universiti Teknologi Malaysia, } \\
81310 \text { UTM Johor Bahru, Johor, Malaysia. } \\
\text { Email: mdkamal@utm.my }\end{array}$} \\
\hline
\end{tabular}

\section{INTRODUCTION}

The history goes way back to the early of $20^{\text {th }}$ century where radar were first introduced as to be used in the military. The first active Identify Friend or Foe (IFF) system were developed where every British plane was equipped with a transmitter so when they are within the range of the radar stations in the ground, the transmitter would send a signal back to identify themselves as a friendly craft. The concept of RFID is similar to that of this system. It was then still considered a secret technology used by the military to restrict the access to sensitive areas such as nuclear plants or buildings. However, RFID cannot be defined as a single technology. RFID are applied in several band of frequencies and different types of tags are developed for various communication methods and different power sources. After that, technological advancements lead to the development of passive tags [1-3].

On that note, for a passive system, a signal would be broadcasted by the reader, and the tag would be powered up by the signal when the transponder or tag is within the range of the reader and a signal would be sent back to the reader. For an active system, the transponder would continuously broadcast its own signal to be read by the reader.

The use of passive UHF RFID systems are still scarce even though it holds better benefits compared to the more commonly used low frequency (LF) and high frequency (HF) RFID systems. Some of the benefits in replacing LF and HF RFID with UHF RFID are the latter have tags that are smaller in size. UHF RFID tags can be as small as a barcode and thinner than paper as the antenna can be printed using conductive ink or conductive tapes. Plus, the production cost of the UHF RFID tags is cheaper compared to the LF and HF RFID tags due to the materials needed to materialise the tags. Moreover, UHF RFID reader can detect the tag up to 
5 meters away meanwhile LF and HF RFID readers can only detect the tags if it is 0 to $0.6 \mathrm{~cm}$ away from the reader [4-7].

The research done in developing compact size UHF RFID tag antennas [8-11] prove to be challenging. For example, authors in [9] designed and developed a quadrate bowtie antenna using printed paper with the size of $9.2 \mathrm{~cm} \times 3.2 \mathrm{~cm}$ for UHF RFID tag. The size of the tag could be further reduced to be applicable in areas such as wearable applications and asset management. Next, the tag developed in [12] is specifically made for wearable application as it is proven to work even when directly attached to human skin. However, the tag is not suitable for long and repeated use as the tag is developed using conductive paint. The material faces the possibility of chipping off or crack with a slight bending. Paper [13] discusses the development of a UHF RFID tag to be placed on shirt collars using copper tape. However, the paper specifically designed the tag to match a complex impedance, the Alien H3 strap. Thus, it could not be applied to tags that does not apply the Alien H3 strap. Nevertheless, the use and application of UHF RFID systems are gaining some popularity this past years [12-20], most of the tags are still considered too big and further studies can be done to make it even smaller so that it could be applied to more situations and uses.

\section{RESEARCH METHOD}

Figure 1 shows the different bowtie-based tag antenna shapes developed for this paper. Figure 1 (a) displays a meander line traced in a general shape of a dipole bowtie antenna. Next, Figure 1 (b) shows a more elongated shape of bowtie antenna with thinner wings. Figure 1 (c) presents a shorter bowtie antenna, but larger wings compared to the general shape shown in Figure 1 (a). Finally, Figure 1 (d) exhibits a meander line traced over a bowtie shape tapered with a circle with radius, $r=100 \mathrm{~mm}$ on the top and the bottom part of the antenna. Figure 2 shows the materials used in developing the UHF RFID tag.

All of the structures are designed and developed on a polycarbonate material or transparency paper with a thickness, $\mathrm{h}=0.21 \mathrm{~mm}$, permittivity, $\varepsilon \mathrm{r}=2.9$, and tangential loss, $\tan \delta=0.008$. The radiating element used is copper tape. Transparency paper is chosen because of its durability and flexibility so that it could be employed in various application such as wearable application. Copper tape is used mainly because it is easy to apply to the substrate, easy to shape, and finally it does not crack or tear when the substrate is bent inside or outside. The materials are placed on the Silhouette Cameo cutting machine where the design of the antenna are loaded and ready to be sent over for cutting process. Since UHF RFID chips have different input impedance, this paper will follow the standard RF antenna design with $50 \Omega$ input impedance.

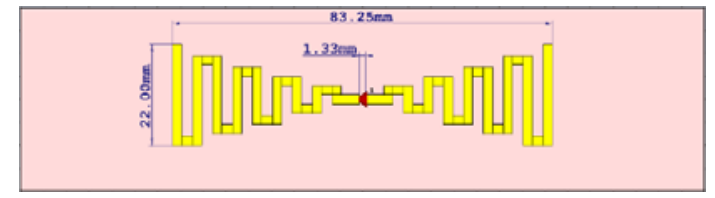

(a) Meander 1

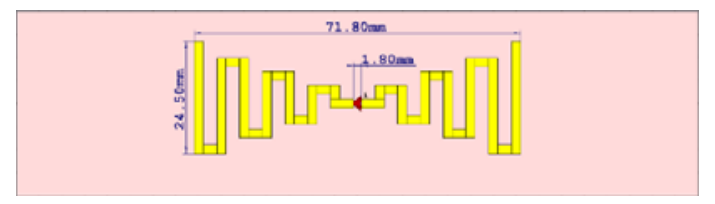

(c) Meander 3

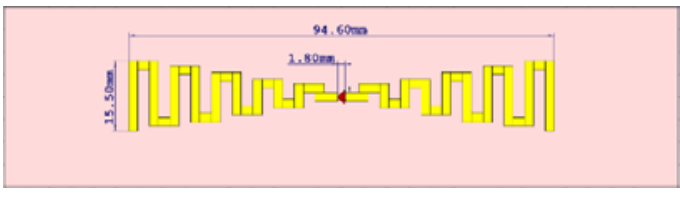

(b) Meander 2

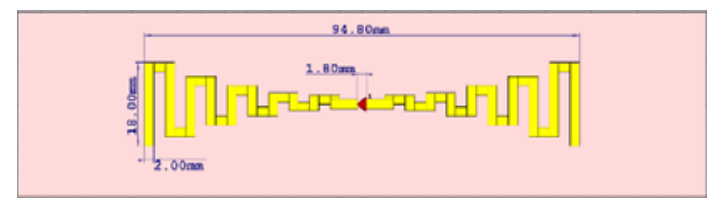

(d) Meander 4

Figure 1. Four shapes of tag antenna chosen to be cut and measured.

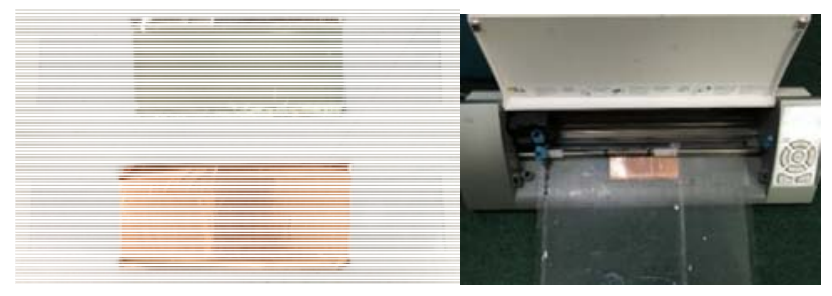

Figure 2. Copper and aluminum tape plastered on transparency on Silhouette Cameo cutting machine. 
After the cutting process, the tape excess on the substrate is removed. Then, a flat surface is placed on top of the substrate and pressure is applied. This is to ensure that there would be no lifting or wrinkles on the antenna. A $50 \Omega$ cable is then attached to the antenna and the measurement process ensued. This tag is not matched towards RFID chips thus, testing it with any RFID chip will not yield its true result. Figure 3 shows the final product of the tag antenna that are ready to be measured for its reflection coefficient and radiation pattern.

Figure 4 shows the reflection coefficient, $\mathrm{S}_{11}$ measurement process using a portable Vector Network Analyzer (VNA). The VNA is calibrated and set to measure the $\mathrm{S}_{11}$ from $0.5 \mathrm{GHz}$ to $1.5 \mathrm{GHz}$.

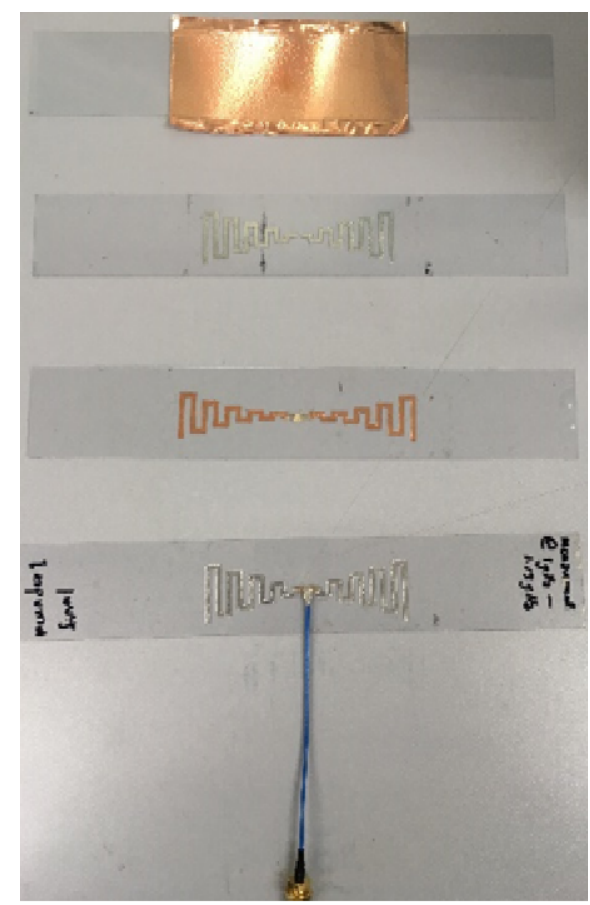

Figure 3. The final UHF RFID tag antenna.

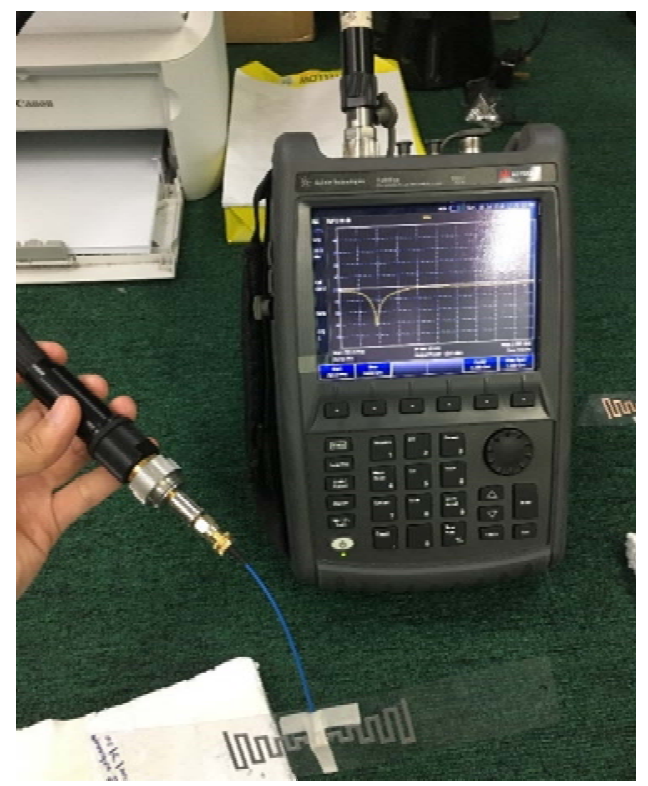

Figure 4. UHF RFID tag antenna are measured using a portable VNA 


\section{RESULTS AND ANALYSIS}

The comparison between simulation results run on CST software and measurement done using the portable VNA for all of the shapes shown in Figure 4 for aluminium as the radiating element are shown below. In figure 5, there are 4 different images of the reflection coefficient. Figure 5 (a) shows the graph of simulated $\mathrm{S}_{11}$ vs the measured $\mathrm{S}_{11}$ of Meander 1 tag antenna. Over all, the measured results shown are in a good agreement with the simulated result. Next, Figure 5 (b) shows the results for Meander 2 tag which also shows similar results of simulated $S_{11}$ and measured $S_{11}$ result. On the other hand, Figure 5 (c) shows a noticeable difference between the simulated and measured $\mathrm{S}_{11}$ results of Meander 3 tag. The measured results shows wider frequency range compared to the simulated result. This is could be due to the interference during measurement or one of many challenges during the fabrication process. Finally, Figure 5 (d) shows a slight frequency shift happening on the measured $S_{11}$ result. This could also happen due to background noise in the lab happening during the measurement process.

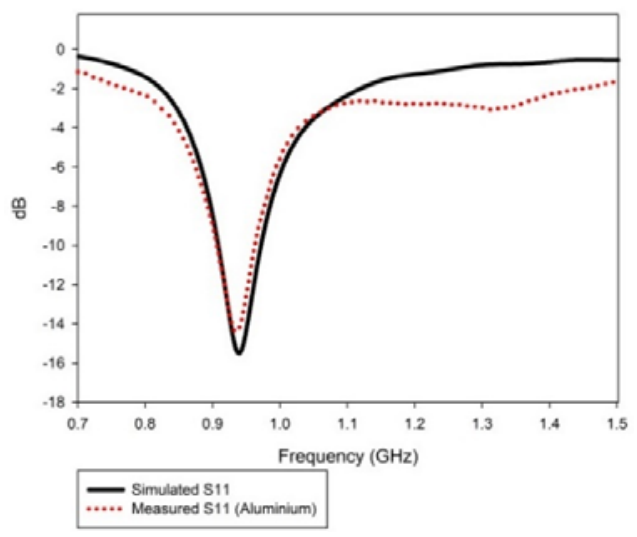

(a) Meander 1

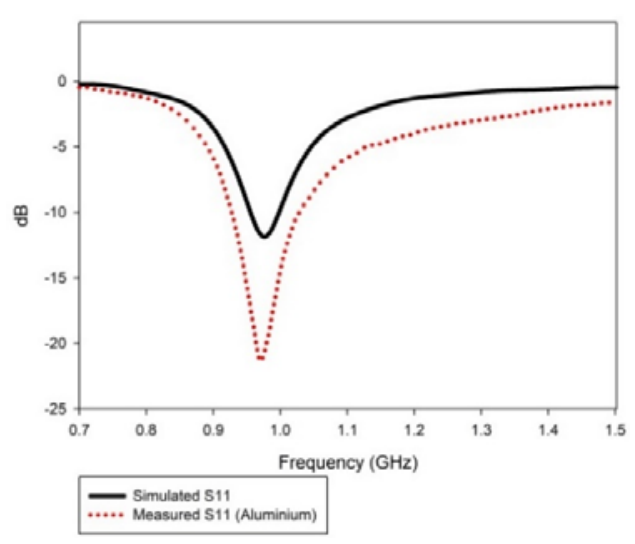

(c) Meander 3

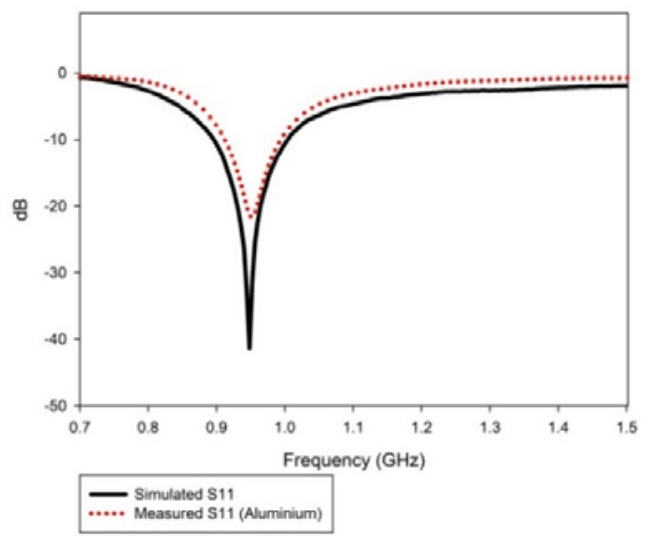

(b) Meander 2

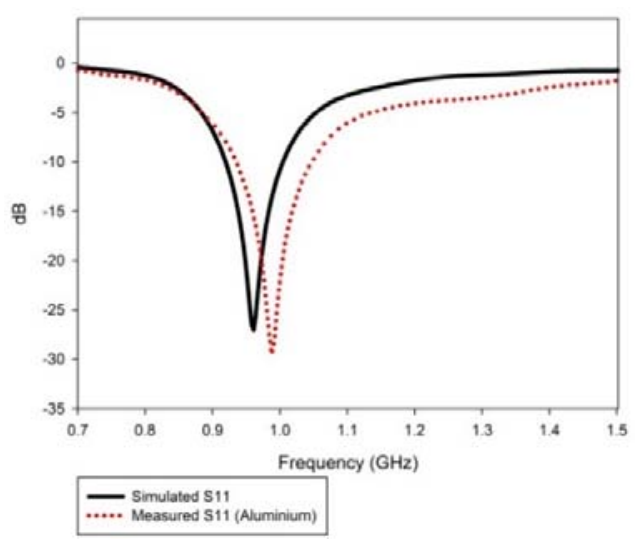

(d) Meander 4

Figure 5. Comparison between simulated and measured $\mathrm{S}_{11}$ for Meander 1 tag antenna

Next, in Figure 6 below shows 8 different images of the radiation pattern measured using VNA in the chamber room. Figure 6 (a) shows the radiation pattern of E and H field of Meander 1 tag antenna. The measured result shows a good agreement with the simulated result. Next, Figure 6 (b) shows the radiation pattern for Meander 2 tag antenna. The E-field shows a slight difference in the centre between the simulated and measured result. However, measurement result conforms to the simulated result. The slight difference displayed is due to the scaling of the graph. This is a common issue that could be fixed with minor adjustment to the graph, however, the graphs are left as is until the measurement result of antenna using different material are available. After that, Figure 6 (c) shows a good agreement between the comparison of simulated and measured radiation pattern of Meander 3 tag antenna. Finally, Figure 6 (d) shows the result obtained for Meander 4 tag antenna. 


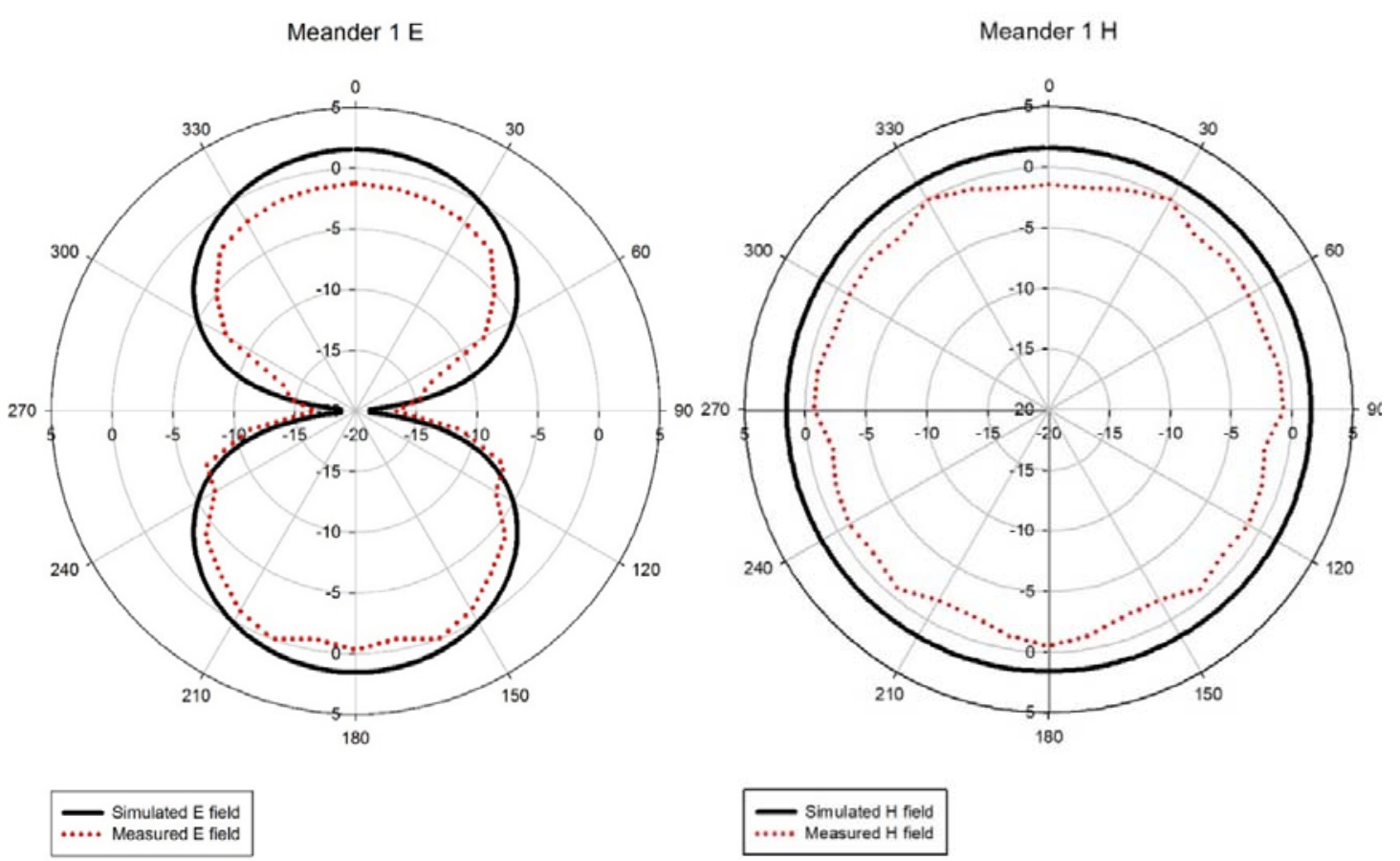

(a) Meander 1 tag antenna

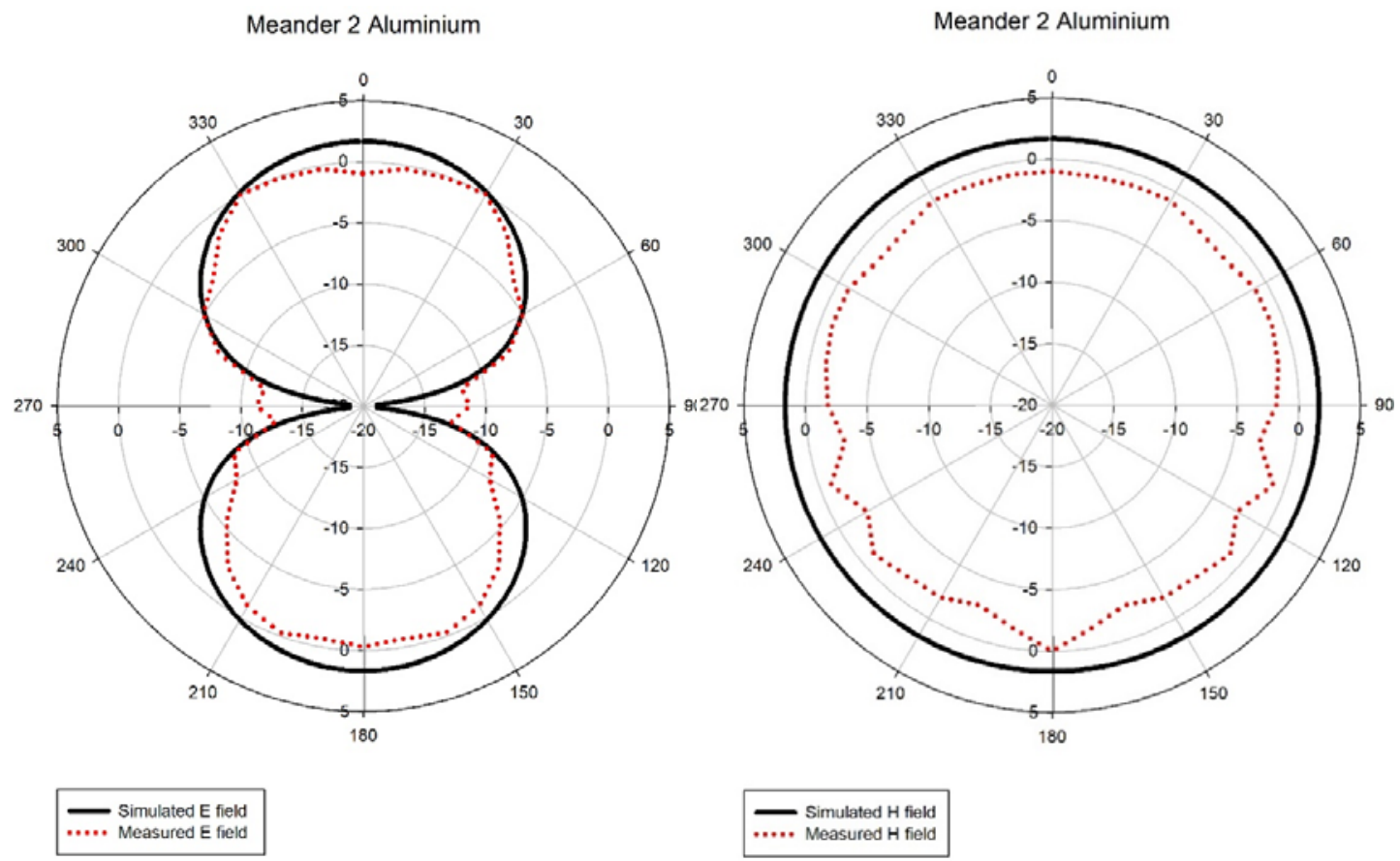

(b) Meander 2 tag antenna 


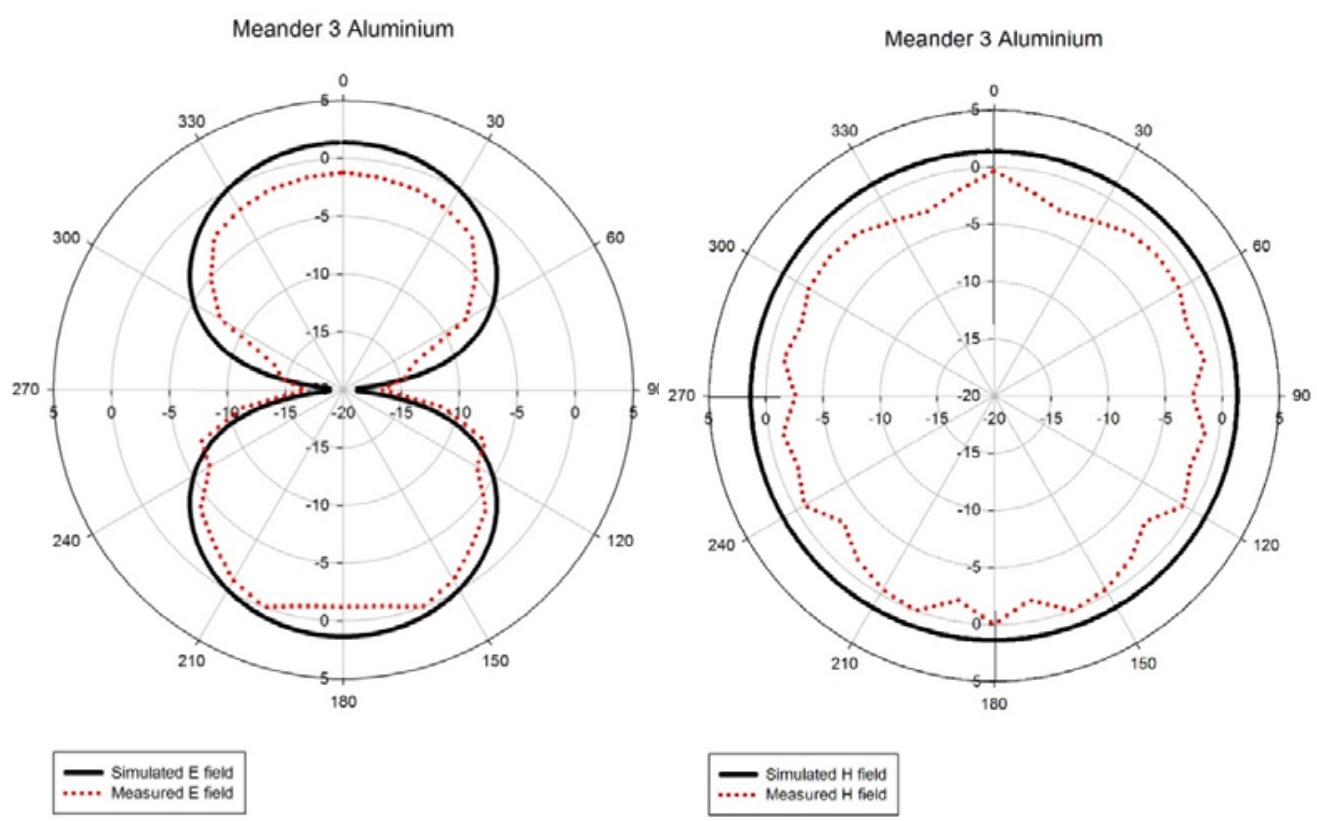

(c) Meander 3 tag antenna

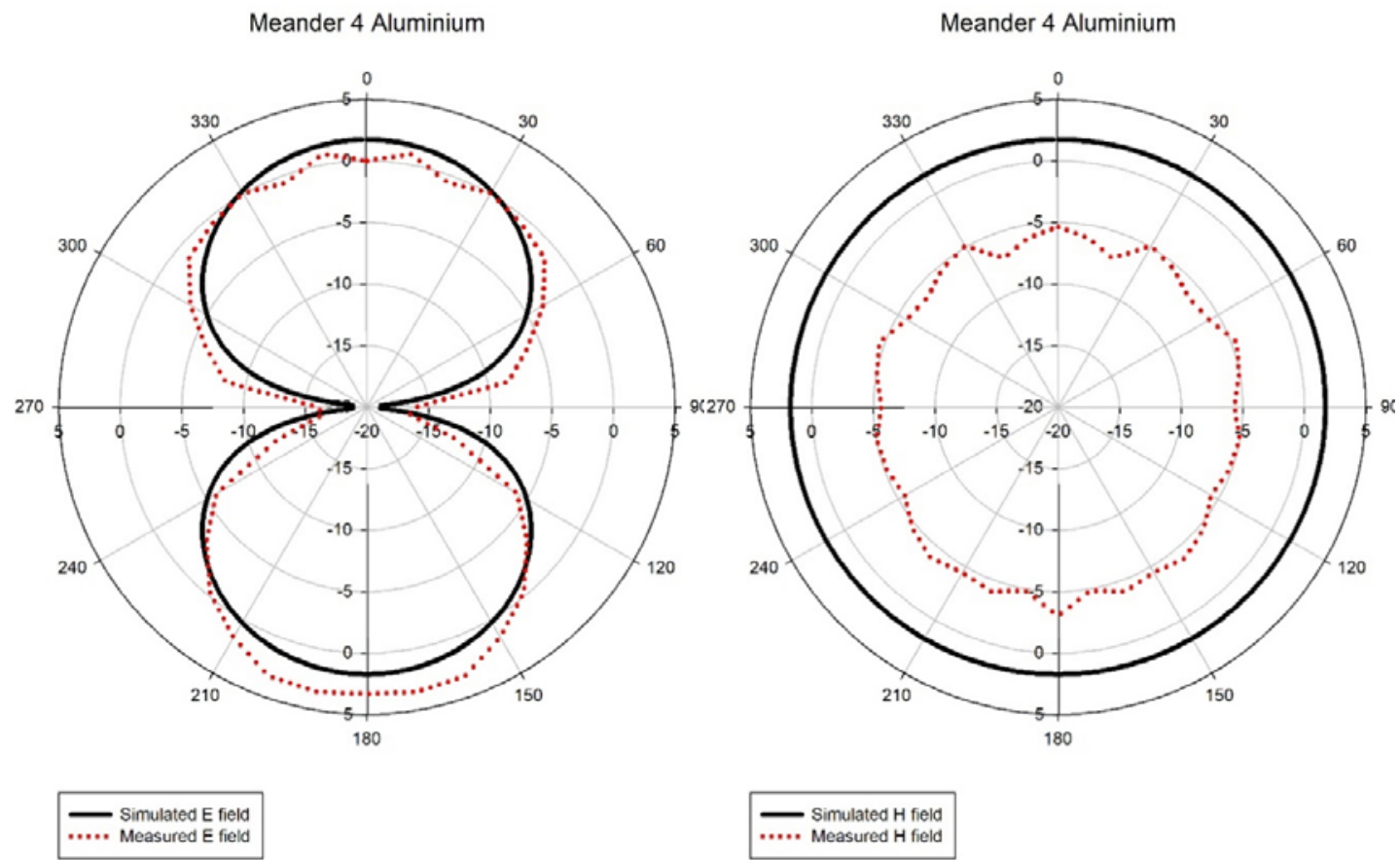

(d) Meander 4 tag antenna

Figure 6. Tag antenna radiation pattern

Table 1 shows the simplified comparison of the frequency range obtained of the simulated and the measured result of reflection coefficient, $\mathrm{S}_{11}$. The results exhibit slight difference if not similar results of simulated and measured frequency range. Out of the four tags antenna, Meander 3 shows the largest contrast between simulated and measured result of almost $0.03 \mathrm{GHz}$ difference and Meander 3 exhibits a slight frequency shift. This is most probably due to the fabrication process where indentation of the radiating element, an aluminium tape, would cause a slight frequency shift during measurement process. 
Table 1. Comparison between simulated and measured $\mathrm{S}_{11}$ of UHF RFID tag antenna

\begin{tabular}{ccc}
\hline UHF RFID tag antenna & $\begin{array}{c}\text { Frequency range from } \\
\text { simulated } \mathrm{S}_{11}(\mathrm{GHz})\end{array}$ & $\begin{array}{c}\text { Frequency range from } \\
\text { measured } \mathrm{S}_{11}(\mathrm{GHz})\end{array}$ \\
\hline Meander 1 & $0.908-0.971$ & $0.908-0.96$ \\
Meander 2 & $0.912-0.993$ & $0.9-1$ \\
Meander 3 & $0.956-0.998$ & $0.928-1$ \\
Meander 4 & $0.919-1$ & $0.936-1.04$ \\
\hline
\end{tabular}

Finally, taking every aspect of the tag characteristics and results, Meander 1 is chosen as the best UHF RFID tag antenna as the overall performance including the size, radiation pattern, and $\mathrm{S}_{11}$ results shows the best parameters compared to the other tag antennas. The summary of Meander 1 tag antenna is presented in Table 2 below.

Table 2. Summary of Meander 1 tag antenna

\begin{tabular}{cc}
\hline Parameter & Value \\
\hline Width, w $(\mathrm{mm})$ & 83.25 \\
Length, 1 $(\mathrm{mm})$ & 22 \\
$\begin{array}{l}\text { Frequency range } \\
\text { simulated }(\mathrm{GHz})\end{array}$ & $0.908-0.971$ \\
$\begin{array}{l}\text { Frequency range } \\
\text { measured }(\mathrm{GHz})\end{array}$ & $0.912-0.96$ \\
\hline
\end{tabular}

\section{CONCLUSION}

The development of a UHF RFID tag antenna using transparency paper as the substrate and aluminium and copper tape as the radiating elements are presented and discussed. The radiation pattern of the tag antennas is shown and the simulation result of the reflection coefficient are compared to the measured result and it can be concluded that only slight difference are noticeable on tag Meander 3 and Meander 4 most probably due to challenges during fabrication process. Finally, a thorough and precise fabrication process would increase the quality of the tags.

\section{ACKNOWLEDGEMENTS}

The authors thank the Ministry of Education (MOE) for supporting the research work; Research Management Centre (RMC), School of Postgraduate Studies (SPS), Communication Engineering Department, Faculty of Electrical Engineering (FKE), and Universiti Teknologi Malaysia (UTM) Johor Bahru for the support of the research under grant no $16 \mathrm{H} 08$. The authors would also like to acknowledge all members of Advanced RF and Microwave Research Group (ARFMRG).

\section{REFERENCES}

[1] Landt, J. "The history of RFID," IEEE potentials, vol. 24(4), pp. 8-11, 2005.

[2] Stockman, H. "Communication by means of reflected power," Proceedings of the IRE, vol. 36(10), pp. 1196-1204, 1948.

[3] Roberti, Mark. "The History of RFID Technology," The History of RFID Technology, RFID Journal, 16 Jan. 2005, www.rfidjournal.com/articles/view?1338.

[4] Pang Y, Ding H, Liu J, Fang Y, Chen S., "A UHF RFID based System for Children Tracking," IEEE Internet of Things Journal, 2018.

[5] Glidden R, Bockorick C, Cooper S, Diorio C, Dressler D, Gutnik V, Hagen C, Hara D, Hass T, Humes T, Hyde J. "Design of ultra-low-cost UHF RFID tags for supply chain applications," IEEE Communications Magazine, vol. 42(8), pp. 140-51, 2004.

[6] Hammer N, Pfeifer M, Staiger M, Adrion F, Gallmann E, Jungbluth T. "Cost-benefit analysis of an UHF-RFID system for animal identification, simul taneous detection and hotspot monitoring of fattening pigs and dairy cows," LANDTECHNIK, vol. 72(3), pp. 130-55, 2017.

[7] Colella R, Catarinucci L, Coppola P, Tarricone L. "Measurement platform for electromagnetic characterization and performance evaluation of UHF RFID tags," IEEE Transactions on Instrumentation and Measurement, vol.65(4), pp. 905-14, 2016.

[8] Marrocco, Gaetano, "RFID antennas for the UHF remote monitoring of human subjects," IEEE Transactions on Antennas and Propagation, vol. 55(6), pp. 1862-1870, 2007.

[9] Amin Y, Prokkola S, Shao B, Hallstedt J, Tenhunen H, Zheng LR., "Inkjet printed paper based quadrate bowtie antennas for UHF RFID tags," In2009 11th International Conference on Advanced Communication Technology, vol. 1, pp. 109-112, 2009. 
[10] Kärkkäinen M., "Increasing efficiency in the supply chain for short shelf life goods using RFID tagging," International Journal of Retail \& Distribution Management, vol. 31(10), pp. 529-36, 2003.

[11] H. Chaabane, E. Perret, and S. Tedjini, "A methodology for the design of frequency and environment robust UHF RFID tags," IEE Trans. Antenna. Propag, vol 59(9), pp. 3436-3441, 2011.

[12] Ziai MA, Batchelor JC., "Temporary on-skin passive UHF RFID transfer tag," IEEE Transactions on Antennas and Propagation, vol. 59(10), pp. 3565-71, 2011.

[13] Kellomäki T, Björninen T, Ukkonen L, Sydänheimo L. "Shirt collar tag for wearable UHF RFID systems," InAntennas and Propagation (EuCAP), 2010 Proceedings of the Fourth European Conference, pp. 1-5, 2010.

[14] Occhiuzzi C, Cippitelli S, Marrocco G., "Modeling, design and experimentation of wearable RFID sensor, IEEE Transactions on Antennas and Propagation, vol. 58(8), pp. 2490-8, 2010.

[15] Rajagopalan H, Rahmat-Samii Y., "On-body RFID tag design for human monitoring applications," InAntennas and Propagation Society International Symposium (APSURSI), IEEE, pp. 1-4, 2010.

[16] Nadzir NM, Rahim MKA, Zubir F, Majid HA., "Long-Range Monitoring System with PDMS Material," Indonesian Journal of Electrical Engineering and Computer Science (IJEECS), vol. 10(3), pp. 974-9, 2018.

[17] Lopez-Soriano S, Parron J., "Wearable RFID tag antenna for healthcare applications," InAntennas and Propagation in Wireless Communications (APWC), 2015 IEEE-APS Topical Conference, pp. 287-290, 2015.

[18] Teng, Chia-Chi, Matthew Leavitt, and Andy Ivie. "A Laboratory Specimen Management System with Commercially Viable RFID Solution." In Proceedings of the 1st International Conference on Medical and Health Informatics 2017, ACM, pp. 42-47, 2017.

[19] Balbin, Jessie R., Ramon G. Garcia, Flordeliza L. Valiente, Brian Christopher F. Aaron, Christopher John D. Celimen, Juan Carlos K. De Peralta, and Joshua P. Despabiladeras. "Vehicle identification system through the interoperability of an ultra high frequency radio frequency identification system and its database." In Humanoid, Nanotechnology, Information Technology, Communication and Control, Environment and Management (HNICEM), 2017 IEEE 9th International Conference, pp. 1-5, 2017.

[20] Zitta, Tomas, Marek Neruda, and Lukas Vojtech. "The security of RFID readers with IDS/IPS solution using Raspberry Pi." In Carpathian Control Conference (ICCC), 2017 18th International on IEEE, pp. 316-320, 2017.

Indo. J. Elec. Eng. \& Inf, Vol.7, No. 2, June 2019: 295 - 302 